\title{
Oceaniserpentilla haliotis gen. nov., sp. nov., a marine bacterium isolated from haemolymph serum of blacklip abalone
}

\author{
Correspondence \\ Andreas Schlösser \\ andreas.schloesser@labor-ls.de
}

\author{
Andreas Schlösser, ${ }^{1}$ André Lipski, ${ }^{2}$ Jochen Schmalfuß, ${ }^{3}$ Frank Kugler ${ }^{1}$ \\ and Gero Beckmann ${ }^{1}$ \\ ${ }^{1}$ Labor L+S AG, Mangelsfeld 4, 97708 Bad Bocklet, Germany \\ ${ }^{2}$ Universität Osnabrück, Barbarastraße 11, 49069 Osnabrück, Germany \\ 3 biosyn Arzneimittel GmbH, Schorndorfer Straße 32, 70734 Fellbach, Germany
}

In the last few years, a large number of strains have been isolated from diverse marine environments (Connon \& Giovannoni, 2002; Allgaier et al., 2003) and many have been identified as representing novel species in new genera. The blacklip abalone Haliotis rubra is endemic mainly to the southern waters of Australia and is one of the most valuable fishery species. Nearly 80 species of abalone are known; they appear in offshore areas worldwide and grow at depths of $0-40 \mathrm{~m}$. In an earlier study, a previously unknown strain of the genus Vibrio, LMG $21323^{\mathrm{T}}$, was isolated from the gut of Haliotis rubra and described as Vibrio superstes (Hayashi et al., 2003). This Gram-negative strain was non-motile, facultatively anaerobic and possessed alginolytic activity.

Abalones were harvested by the fishery industry near Hobart, Tasmania $\left(42^{\circ} 55^{\prime} \mathrm{S} 147^{\circ} 20^{\prime} \mathrm{E}\right)$, in February 2006. Isolate DSM $19503^{\mathrm{T}}$ was obtained from haemolymph serum prepared from Haliotis rubra. The haemolymph serum was filtered through a sterile filter with a pore size of

The GenBank/EMBL/DDBJ accession number for the 16S rRNA gene sequence of strain DSM $19503^{\top}$ is AM747817.
$0.2 \mu \mathrm{m}$ and stored at $2-8{ }^{\circ} \mathrm{C}$. After several months, bacterial growth was detected in the filtered haemolymph sera and samples were subjected to microbial investigations. Isolates of strain DSM $19503^{\mathrm{T}}$ were grown on Columbia blood agar supplemented with $1.5 \% \mathrm{NaCl}$ after incubation for 14 days at $2-8{ }^{\circ} \mathrm{C}$ as tiny, opaque colonies. The growth period of strain DSM $19503^{\mathrm{T}}$ could be decreased to $3-4$ days incubation at $22{ }^{\circ} \mathrm{C}$ by plating on fresh Columbia blood agar supplemented with $1.5 \% \mathrm{NaCl}$. Colonies reached a maximum size of 2-3 mm after 1 week and haemolytic activity was observed around the colonies. Strain DSM $19503^{\mathrm{T}}$ could also be grown on marine agar 2216 (Difco). When grown on Columbia blood agar and suspended in NaCl-supplemented seawater medium, the isolate exhibited weak reactions for utilization of Tweens 40 and 80 after 9 days of incubation at $22{ }^{\circ} \mathrm{C}$, using the Biolog substrate panel. Using API ID $32 \mathrm{GN}$ and API ID 20 $\mathrm{NE}$ test kits (bioMérieux), the strain utilized L-alanine, L-proline, L-arabinose, caproic acid, 3-hydroxybutyric acid and potassium 5-keto-D-gluconate after incubation of the test kits for $96 \mathrm{~h}$ at $22{ }^{\circ} \mathrm{C}$. Cellular morphology and motility of the isolate were observed by using 
phase-contrast microscopy (Fig. 1). The novel isolate was Gram-negative, vibrioid to spiral, non-spore-forming, about $1.8-3.5 \mu \mathrm{m}$ long by $0.2-0.6 \mu \mathrm{m}$ wide and highly motile. Oxidase activity was detected, whereas catalase activity was absent. For long-term preservation, cryopreservation at below $-80{ }^{\circ} \mathrm{C}$ using Microbank vials (Prolab) was feasible. In contrast, lyophilized cells in $10 \%$ skimmed milk lost viability.

Fatty acid analysis was performed on the isolate and two reference strains using cells grown on seawater agar and on $\mathrm{NaCl}$-supplemented Columbia blood agar for 10 days at $22{ }^{\circ} \mathrm{C}$. Growth of Oleispira antarctica DSM $14852^{\mathrm{T}}$ was only obtained on seawater agar, whereas Marinomonas vaga ATCC $27119^{\mathrm{T}}$ failed to grow on seawater agar and instead grew only on $\mathrm{NaCl}$-supplemented Colombia blood agar. Saponification with $15 \% \mathrm{NaOH}$ in $50 \%$ methanol, acid methylation with $6 \mathrm{M} \mathrm{HCl}$ in $50 \%$ methanol and extraction of fatty acid methyl esters were performed as described by Sasser (1990). The fatty acid methyl ester extracts were analysed by GC (Hewlett Packard model 6890) equipped with a $5 \%$ phenyl-methyl-silicone capillary column and a flame ionization detector. The identity of the fatty acids was verified by GC-MS (Hewlett Packard model 5890 series II equipped with a $5 \%$ phenyl-methyl-silicone capillary column and a model 5972 MS detector). The chromatographic conditions used were described previously (Lipski \& Altendorf, 1997). The positions of double bonds were verified by analysing the dimethyl-disulfide adducts of the fatty acid methyl esters. The positions of hydroxy and methoxy groups and double bonds are given from the carboxyl group of the fatty acid molecule

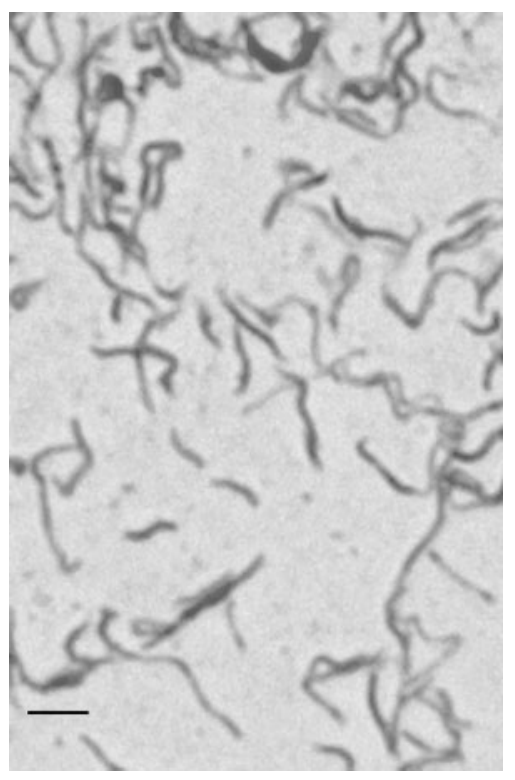

Fig. 1. Light micrograph of cells of strain DSM $19503^{\top}$ grown on Columbia blood agar with $1.5 \% \mathrm{NaCl}$ for 14 days at $22^{\circ} \mathrm{C}$. Bar, $2 \mu \mathrm{m}$. according to the recommendations of the IUPAC-IUB Commission on Biochemical Nomenclature (1977).

The fatty acid composition of cells grown on Columbia blood agar differed from that of cells cultivated on seawater agar. Large amounts ( $62.7 \%$ of total fatty acids) of $\mathrm{C}_{10: 0} 3-$ $\mathrm{OH}(11.8 \%), \mathrm{C}_{12: 1}$ cis5 (8.2\%), $\mathrm{C}_{16: 1}$ cis $(29.6 \%)$ and $\mathrm{C}_{18: 1}$ cis9 $(13.1 \%)$ were found in cells grown on Columbia blood agar (Table 1). When grown on seawater agar, the principal saturated fatty acids were $\mathrm{C}_{14: 0}(1.4 \%), \mathrm{C}_{16: 0}$ $(90.3 \%)$ and $\mathrm{C}_{18: 0}(2.9 \%)$, representing more the fatty acid synthesis pathways of isolate DSM $19503^{\mathrm{T}}$. The fatty acid profile of strain DSM $19503^{\mathrm{T}}$ cultivated on seawater agar was highly similar to that of the reference strain Oleispira antarctica DSM $14852^{\mathrm{T}}$, with palmitic acid as the dominant compound and $\mathrm{C}_{10: 0} 3-\mathrm{OH}$ as hydroxyl fatty acid.

For 16S rRNA gene sequence analysis, cells of strain DSM $19503^{\mathrm{T}}$ were lysed with the PrepMan Ultra preparation reagent (Applied Biosystems). Amplification of the $16 \mathrm{~S}$ rRNA gene was performed using the PCR-MicroSeq Full Gene $16 \mathrm{~S}$ rDNA PCR kit (Applied Biosystems). Amplified PCR products were purified using the QIAquick PCR Purification kit (Qiagen). Sequencing reactions were carried out using the MicroSeq Full Gene 16S rDNA sequencing kit (Applied Biosystems). Sequencing products were purified with the DyeEx 2.0 spin kit (Qiagen).

Table 1. Fatty acid compositions (\%) of Oceaniserpentilla haliotis DSM $19503^{\top}$ and the reference strains Oleispira antarctica DSM $14852^{\top}$ and Marinomonas vaga ATCC $27119^{\top}$

Strains/growth conditions: 1, Oceaniserpentilla haliotis DSM $19503^{\mathrm{T}}$ grown on seawater agar; 2, Oceaniserpentilla haliotis DSM $19503^{\mathrm{T}}$ grown on blood/NaCl agar; 3, Oleispira antarctica DSM $14852^{\mathrm{T}}$ grown on seawater agar; 4, Marinomonas vaga ATCC $27119^{\mathrm{T}}$ grown on blood/NaCl agar. ND, Not detected.

\begin{tabular}{|lrrrr|}
\hline Fatty acid & $\mathbf{1}$ & $\mathbf{2}$ & $\mathbf{3}$ & $\mathbf{4}$ \\
\hline $\mathrm{C}_{10: 0}$ & 0.1 & 2.7 & 0.8 & 3.7 \\
$\mathrm{C}_{10: 0}$ 3-methoxy & $\mathrm{ND}$ & 0.3 & $\mathrm{ND}$ & 0.2 \\
$\mathrm{C}_{10: 0}$ 3-OH & 1.0 & 11.8 & 1.0 & 18.7 \\
$\mathrm{C}_{12: 1}$ cis 5 & 1.2 & 8.2 & 2.3 & 3.0 \\
$\mathrm{C}_{12: 0}$ & 0.4 & 2.2 & 1.5 & 4.2 \\
$\mathrm{C}_{12: 0} 3-\mathrm{OH}$ & $\mathrm{ND}$ & $\mathrm{ND}$ & 1.5 & 0.2 \\
$\mathrm{C}_{14: 0}$ & 1.4 & 0.6 & 1.6 & 1.7 \\
$\mathrm{C}_{16: 1}$ cis 9 & 1.3 & 29.6 & 7.0 & 16.7 \\
$\mathrm{C}_{16: 1}$ trans 9 & $\mathrm{ND}$ & 0.6 & 1.3 & 0.5 \\
$\mathrm{C}_{16: 1}$ cis 11 & $\mathrm{ND}$ & 0.3 & 0.1 & 0.1 \\
$\mathrm{C}_{16: 0}$ & 90.3 & 19.3 & 80.9 & 9.4 \\
$\mathrm{C}_{17: 0}$ & 0.1 & 0.3 & 0.1 & $\mathrm{ND}$ \\
$\mathrm{C}_{18: 2}$ cis 9,12 & $\mathrm{ND}$ & 1.3 & 0.9 & 0.4 \\
$\mathrm{C}_{18: 1}$ cis 9 & 0.6 & 13.1 & $\mathrm{ND}$ & 0.4 \\
$\mathrm{C}_{18: 1}$ cis 11 & 0.2 & 3.6 & 0.1 & 38.9 \\
$\mathrm{C}_{18: 1}$ trans 11 & $\mathrm{ND}$ & $\mathrm{ND}$ & $\mathrm{ND}$ & 0.4 \\
$\mathrm{C}_{18: 0}$ & 2.9 & 4.8 & 0.8 & 0.9 \\
$\mathrm{C}_{19: 0}$ & $\mathrm{ND}$ & 0.4 & $\mathrm{ND}$ & $\mathrm{ND}$ \\
\hline
\end{tabular}




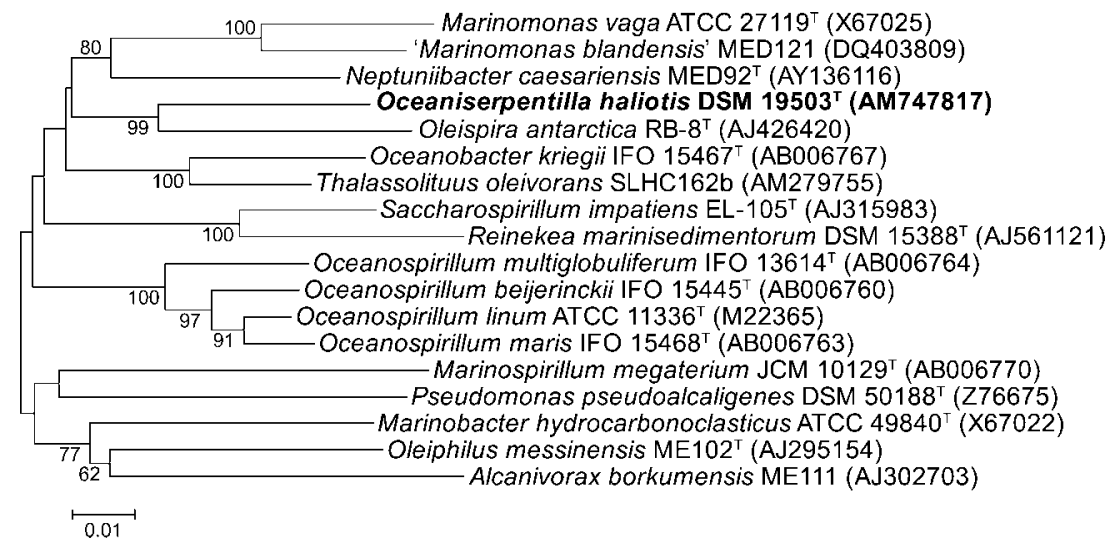

Fig. 2. Dendrogram of $16 \mathrm{~S}$ rRNA gene sequence relatedness showing the phylogenetic position of strain Oceaniserpentilla haliotis DSM $19503^{\top}$ and most closely related type strains within the Oceanospirillaceae. Numbers at branching points refer to bootstrap values (1000 resamplings). Bar, genetic distance of 1 nucleotide substitution per 100 nucleotides.

Analysis of the sequencing reactions was performed with the 3100-Avant Genetic Analyzer (Applied Biosystems). The nearly complete $16 \mathrm{~S}$ rRNA gene sequence (1475 bp) of isolate DSM $19503^{\mathrm{T}}$ was obtained by sequencing both strands at least twice. Initial sequence comparisons against the 16S rRNA gene sequences available in the Ribosomal Database Project (Maidak et al., 2001) and the FASTA33 database (Pearson, 1990) indicated that the strain belongs to the class Gammaproteobacteria, with highest sequence similarity of $97.5 \%$ to an undescribed gammaproteobacterial isolate Gp_4_7.1 (GenBank accession no. AM117931) and a similarity of $92.9 \%$ to the next related type strain, which was Oleispira antarctica RB-8 ${ }^{\mathrm{T}}$ (AJ426420).

A phylogenetic tree based on $16 \mathrm{~S}$ rRNA gene sequences of type strains with highest nucleotide similarity was constructed using the program MEGA (Tamura et al., 2007). Neighbour-joining analysis revealed that strain DSM $19503^{\mathrm{T}}$ formed a branch together with Oleispira antarctica RB- $8^{\mathrm{T}}$ (bootstrap value of $99 \%$ ) within the family Oceanospirillaceae (Fig. 2). Generally, the threshold of sequence similarity to separate species based on the $16 \mathrm{~S}$ rRNA gene is $97 \%$ (Stackebrandt \& Goebel, 1994); the phylogenetic distance of the novel isolate from Oleispira antarctica suggests that the isolate represents a novel species in a new genus within the family Oceanospirillaceae, Oceaniserpentilla haliotis gen. nov., sp. nov.

\section{Description of Oceaniserpentilla gen. nov.}

Oceaniserpentilla (O.ce.a.ni.ser.pen.til'la. L. masc. n. oceanus the ocean; L. fem. n. serpens -tis a snake; N.L. fem. n. serpentilla a small snake; N.L. fem. n. Oceaniserpentilla small snake of the ocean, indicating shape and origin).

Gram-negative, motile, obligately aerobic, vibrioid to spiral, non-spore-forming cells. Oxidase activity is present, whereas catalase activity is absent. A member of the family Oceanospirillaceae. The type species is Oceaniserpentilla haliotis.

\section{Description of Oceaniserpentilla haliotis sp. nov.}

Oceaniserpentilla haliotis (ha.li.o'tis. N.L. n. Haliotis scientific name of a genus; N.L. gen. n. haliotis of
Haliotis, referring to the isolation of the type strain from Haliotis rubra).

Cells are about $1.8-3.5 \mu \mathrm{m}$ long by $0.2-0.6 \mu \mathrm{m}$ wide and highly motile. Grows on seawater agar or Columbia blood agar with $1.5 \% \mathrm{NaCl}$ and in abalone haemolymph serum. Psychrophilic, with optimal growth at $2-8{ }^{\circ} \mathrm{C}$. Cultivation time to the appearance of tiny colonies of about $0.5 \mathrm{~mm}$ in diameter is $10-14$ days. Growth can be adapted to $22^{\circ} \mathrm{C}$. Weak reactions for utilization of Tweens 40 and 80. Utilizes L-alanine, L-proline, L-arabinose, caproic acid, 3-hydroxybutyric acid and potassium 5-keto-D-gluconate. The cellular fatty acid composition is highly dependent on the growth medium. When grown on seawater agar, the principal saturated fatty acids are $\mathrm{C}_{14: 0}(1.4 \%), \mathrm{C}_{16: 0}(90.3 \%)$ and $\mathrm{C}_{18: 0}(2.9 \%)$, whereas Columbia blood agar/ $\mathrm{NaCl}$-grown cells exhibit mainly $\mathrm{C}_{10: 0} 3-\mathrm{OH}(11.8 \%), \mathrm{C}_{12: 1}$ cis5 (8.2\%), $\mathrm{C}_{16: 1} \operatorname{cis} 9(29.6 \%), \mathrm{C}_{16: 0}(19.3 \%)$ and $\mathrm{C}_{18: 1} \operatorname{cis} 9(13.1 \%)$.

The type strain is DSM $19503^{\mathrm{T}}\left(=\mathrm{LMG} 24225^{\mathrm{T}}\right)$, isolated after filtration of abalone haemolymph serum through a filter with a pore size of $0.2 \mu \mathrm{m}$. The haemolymph serum was isolated from the blacklip abalone Haliotis rubra harvested near Hobart, Tasmania. No bacterial species with a validly published name shows more than $92.9 \% 16 \mathrm{~S}$ rRNA gene sequence similarity to the type strain.

\section{Acknowledgements}

We are indebted to Katja Renninger for assistance in the biochemical and morphological strain description. We thank Hans Trüper (University of Bonn) for helpful advice and corrections of the bacterial name.

\section{References}

Allgaier, M., Uphoff, H., Felske, A. \& Wagner-Döbler, I. (2003). Aerobic anoxygenic photosynthesis in Roseobacter clade bacteria from diverse marine habitats. Appl Environ Microbiol 69, 5051-5059.

Connon, S. A. \& Giovannoni, S. J. (2002). High-throughput methods for culturing microorganisms in very-low-nutrient media yield diverse new marine isolates. Appl Environ Microbiol 68, 3878-3885.

Hayashi, K., Moriwaki, J., Sawabe, T., Thompson, F. L., Swings, J., Gudkovs, N., Christen, R. \& Ezura, Y. (2003). Vibrio superstes sp. nov., 
isolated from the gut of Australian abalones Haliotis laevigata and Haliotis rubra. Int J Syst Evol Microbiol 53, 1813-1817.

IUPAC-IUB Commission on Biochemical Nomenclature (1977). The nomenclature of lipids (recommendations 1976). Eur J Biochem 79, 11-21.

Lipski, A. \& Altendorf, K. (1997). Identification of heterotrophic bacteria isolated from ammonia-supplied experimental biofilters. Syst Appl Microbiol 20, 448-457.

Maidak, B. L., Cole, J. R., Lilburn, T. G., Parker, C. T., Jr, Saxman, P. R., Farris, R. J., Garrity, G. M., Li, B., Olsen, G. J., Schmidt, T. M. \& Tiedje, J. M. (2001). The RDP-II (Ribosomal Database Project). Nucleic Acids Res 29, 173-174.
Pearson, W. R. (1990). Rapid and sensitive sequence comparison with FASTP and FASTA. Methods Enzymol 183, 63-98.

Sasser, M. (1990). Identification of bacteria through fatty acid analysis. In Methods in Phytobacteriology, pp. 199-204. Edited by Z. Klement, K. Rudolph \& D. C. Sands. Budapest: Akademiai Kiado.

Stackebrandt, E. \& Goebel, B. M. (1994). Taxonomic note: a place for DNA-DNA reassociation and 16S rRNA sequence analysis in the present species definition in bacteriology. Int J Syst Bacteriol 44, 846-849.

Tamura, K., Dudley, J., Nei, M. \& Kumar, S. (2007). MEGA4: molecular evolutionary genetics analysis (MEGA) software version 4.0. Mol Biol Evol 24, 1596-1599. 